\title{
Pain in Public and Private Places
}

\author{
Joel Katz
}

l: $\mathrm{n}$ the focus article, Sullivan challenges a commonly held view that pain is a private, subjective experience. He argues that our experience of pain is inescapably conceptual, as it arises into our consciousness having been shaped and filtered by language. As conceptual, pain is essentially a social phenomenon. Sullivan also states that a social conception of pain implies changes in our treatment of pain and he concludes by rejecting the cognitivebehavioral view of pain in favor of a constructivist approach that acknowledges the generative influence of language on experience.

\section{PAIN IS PRIVATE AND PUBLIC}

Science seeks to uncover truth through the experimental method. Inferences about the causes of observed phenomena are made, specific hypotheses are generated and tested, and, from the data obtained, a temporary reality is constructed for further evaluation. Many propositions, however, are not falsifiable and therefore are not amenable to this process of empirical refinement. The proposition that pain is an inherently private event or that it is an essentially social phenomenon falls within the realm of the empirically untestable. It is not quite like one's personal religious conviction-either one believes, does not believe, or one is unsure. For after reading Sullivan's article, although I was not swayed from my belief that pain is a private event, I was persuaded that it is also a public phenomenon.

\section{SOCIAL NATURE OF PAIN}

Sullivan's view provides us with a better understanding of how, through the use of language, pain becomes a social phenomenon. Perhaps most importantly, it points

From the Department of Psychology, The Toronto Hospital, and the Departments of Behavioural Science and Anaesthesia, University of Toronto, Toronto, Ontario, Canada.

Reprint requests: Joel Katz, PhD, Department of Psychology, The Toronto Hospital, 200 Elizabeth Street, CW 2-306, Toronto, Ontario, Canada, M5G 2C4. us in the direction - which some have already taken-of trying to understand the social nature of pain from cultural, societal, and familial perspectives. Sullivan is convincing in his argument that the Cartesian view of pain as a private experience has hampered the study of pain as a social phenomenon. Only recently have researchers begun to investigate pain within families and marital dyads. Ironically, a major impetus for the shift to include the larger social context has come from the behavioral perspective. For example, specific pain behaviors (e.g., sighing, limping, or avoiding duties) unwittingly may be reinforced (positively or negatively) by a wellintentioned spouse, thus leading to an increase in the frequency of occurrence of these behaviors. Recent studies have shown that spouses of chronic pain patients may become discriminative cues not only for their partners' pain behaviors ${ }^{4,12,19}$ but also for ratings of pain severity. 2,12,19 The complexity of the social nature of pain is underscored by studies that show that pain patients who are satisfied with their level of social support exhibit more pain behaviors than those who are less satisfied, ${ }^{5}$ and patients with solicitous spouses tend to report higher levels of marital satisfaction. ${ }^{4}$ Moreover, reports from highly solicitous spouses indicate that while their partner's pain problem interferes significantly with their lives, they (the spouses) report better mood and a greater sense of control over their own lives than do less solicitous spouses. ${ }^{4}$ Finally, the degree of solicitousness appears to interact with pain severity and marital satisfaction. Within a satisfying marital relationship, patients with solicitous spouses report greater pain severity than patients with nonsolicitous spouses. However, when marital satisfaction is low, the degree of spouse solicitousness appears to be unrelated to pain severity. ${ }^{11}$

Other studies have confirmed the importance of pain as a social phenomenon. The interpersonal strife that comes to define the lives of many couples with pain affects other close relatives as well. Children from families in which one parent suffers from chronic pain may be at greater risk for developing adjustment disorders, ${ }^{18}$ depressive symptomology, ${ }^{3}$ or other illnesses, ${ }^{17}$ compared with children from healthy families or families in 
which one parent has a chronic disease. At present, the etiology and developmental course of these adjustment problems remain a mystery. We do not know the extent to which the behavior problems observed among offspring of chronic pain patients stem from parental modeling, socialization, reinforcement contingencies, global family stress, or genetic factors. ${ }^{18}$ Nor do we know whether they represent precursors of a chronic pain disorder. A better understanding of these phenomena can only be achieved by further study of the social nature of pain.

\section{LANGUAGE AND PHANTOM LIMB PAIN}

The only way I can describe it now, is like looking out the window, but the window is frosted. You see what is there, but you don't see the sharp edges of everything. Or, if you touch somebody but there's something on the skin so you don't touch the skin, but you feel the skin ... it can be very intense even if it is like that .... the feeling is excessive, but it's not a pain like if you cut yourself or banged yourself. It's not that kind of pain. I can't call it a pain. It's not a pain. It's not a physical pain, I would say, because that (motioning to the space below the stump) is not physical . . . and it is. So, how can I describe something that is physical and is not? It's physical in the way that I feel it, but it's not there. So how do you describe something like that? So it's painful but it's not a pain. I don't know what else to say. - Transcript of audiotaped interview with an amputee describing her phantom limb pain.

Pain words are descriptive labels for sensations. At the same time they are also vehicles for defining the nature of the relationship between communicating parties. These descriptive and relationship (or social) aspects of language can and do coexist-notwithstanding Sullivan's rejection of pain words as descriptors. But the role of language is probably even more complex than we think. Language appears to facilitate integration of information from various sense modalities. ${ }^{10}$ Consider one woman's bittersweet description of the pins-and-needles sensation (paresthesias) so characteristic of phantom limbs, as "champagne bubbles and blisters" after a left shoulder amputation simultaneously marked the end of a prolonged period of suffering and the beginning of life without an arm. ${ }^{8}$ Or, consider the patient with diabetes mellitus who describes the burning pain of a putrefying and discolored gangrenous ulcer on his toe as "hellfire and brimstone." The analogic aspect of the verbal message conveys meaning by likening certain qualities (e.g., sensory) of the pain experience to some other experience-whether fancied or real-and is aided by using such figures of speech as simile, metaphor, and hyperbole, or more subtly through allegory. The formation of a higher-order poly- modal representation of a pain is facilitated by the unifying verbal response that captures the entire experience signaled by the contiguous activation of modality-specific representations arising from separate sensory channels (e.g., visual, olfactory, somatosensory). In this context, language functions simultaneously to access multimodal representations, strengthen their interconnections, and, through convergence of input to neocortical association areas, facilitate both the formation of a pain memory as well as its reactivation after amputation. ${ }^{10}$

\section{THE McGILL PAIN QUESTIONNAIRE (MPQ) AND THE LANGUAGE OF PAIN}

Sullivan's claim that statements such as " no pain, no gain' should have greater clinical importance than the endorsement of either 'pricking' or 'excruciating'" misses an important contribution that pain questionnaires such as the McGill Pain Questionnaire (MPQ) have established, namely, diagnostic utility based on description. One of the most useful features of the MPQ is its potential value as an aid in the differential diagnosis between various pain syndromes. ${ }^{14}$ Melzack et al. ${ }^{15}$ provided evidence of the capacity of the MPQ to discriminate between two types of facial pain. Fifty-three patients were given thorough neurological examinations that led to a diagnosis of either trigeminal neuralgia or atypical facial pain. Each patient rated his or her pain using the MPQ and the scores were submitted to a discriminant analysis. Ninety-one percent of the patients were correctly classified using seven key descriptors. To determine how well the key descriptors were able to predict either diagnosis, the discriminant function was applied to MPQ scores obtained from an independent validation sample of patients with trigeminal neuralgia or atypical facial pain. The results showed a correct prediction for $90 \%$ of the patients. Specific verbal descriptors of the MPQ have also been shown to discriminate between reversible and irreversible damage of the nerve fibers in a tooth, ${ }^{6}$ and between leg pain caused by diabetic neuropathy and leg pain arising from other cause. ${ }^{13}$ Jerome et al. ${ }^{9}$ further showed that the MPQ discriminates between cluster headache pain and other vascular (migraine and mixed) headache pain. It is clear that there are appreciable and quantifiable differences in the way various types of pain are described, and that patients with the same disease or pain syndrome tend to use remarkably similar words to communicate what they feel. The language of pain is a language of description.

\section{TREATMENT IMPLICATIONS OF PAIN AS CONCEPTUAL AND PUBLIC}

Sullivan claims that one important treatment implication of viewing pain as conceptual and public is that the "dis- 
tinction between respondent and operant pain behavior disappears. Once pain language develops, all pain has reflexive and social elements." While it is true that pain is complex, one must question the presumption that because a phenomenon can be viewed from multiple perspectives or divided into multiple elements, the distinction between the elements disappears. For example, we do not ignore the distinction between the content and relationship elements of communication even though every communication contains both elements. ${ }^{22} \mathrm{~A}$ spouse of a pain patient may remind his partner that it is time to take her pain medication in a solicitous manner (e.g., "Here, I've brought you your pills to take") or in a critical, punishing way (e.g., "Have you forgotten to take your pills again?") Both communications have the same content or report aspect but differ in the relationship or command aspect. Should we propose to eliminate the distinction between these elements of communication even though all communications simultaneously inform and command us?

Sullivan does not specify how the absence of a distinction between respondent and operant pain behavior would facilitate treatment. Before we abandon the distinction, we need explicit information on what treatment advantage would be conferred to the patient by not distinguishing between them. As conceptualized from the behavioral perspective, the advantage of distinguishing between respondent and operant pain behaviors is that they are maintained by different environmental contingencies and thus have different implications for treatment. For example, patients with post-traumatic chronic pain syndrome ${ }^{16}$ respond well to a combination of exercise therapy, biofeedback, and group supportive therapy, but it is not until systematic desensitization is introduced that the respondent or classically conditioned pain behaviors are extinguished. In some cases, desensitization also leads to a further decrease in pain severity. Doing away with the distinction simply because we exhibit complex behaviors strikes me as a step backward.

\section{COGNITIVE-BEHAVIOR THERAPY, ILLUSIONS OF HEALTH, AND THE DEPRESSIVE REALISM HYPOTHESIS}

Sullivan may be selling cognitive-behavior therapy short when he dismisses it in favor of a constructivist approach on the basis of "data suggesting that mental health is not synonymous with the accurate perception of interpersonal situations." Sullivan does not provide a balanced view of the controversy over whether depressed persons perceive situations more accurately than nondepressed persons. The position Sullivan adopts is based on the depressive realism hypothesis that nondepressed persons exhibit self-serving biases and distortions, whereas depressed persons do not. Recent work has challenged the validity of these claims. ${ }^{1,20}$ Many of the studies that purport to support depressive realism do not provide an objective standard against which to evaluate the claim. Moreover, of the studies that do provide such a standard, almost half fail to support the claim that dysphoric or depressed individuals display a more accurate or realistic perception than nondepressed individuals. Finally, the majority of studies have evaluated this hypothesis in dysphoric subjects and not among clinically depressed patients. The equivocal nature of these results indicates that depressive realism remains a hypothesis and not a fact.

While this is not the forum to discuss the similarities and differences between the cognitive-behavioral and constructivist approaches, it should be noted that the main objective of cognitive therapy for chronic pain is not, as Sullivan claims, "to correct a distorted interpretation of sensory events." Specific cognitive strategies may be used by cognitive-behavioral therapists to help patients learn to cope with pain through responsetransformation imagery, ${ }^{7}$ but few cognitive therapists would agree with the statement that the problem of chronic pain is a problem of distorting sensory events. Turk and Meichenbaum ${ }^{21}$ provide a concise description of cognitive-behavioral therapy:

A central feature of the cognitive-behavioural treatment is to facilitate the emergence of a new conceptualisation of pain during the course of treatment, thereby permitting the patient's symptoms to be viewed as circumscribed and addressable problems, rather than as vague, undifferentiated, overwhelming experience (pp. 1339-1340).

Ultimately, the value of constructivist therapies for chronic pain will be determined on theoretical and practical grounds-are they sufficently unique in their theoretical underpinnings and predictions and do they help? One would hope this endeavor is undertaken with the same degree of experimental rigor that has characterized the validation of behavioral and cognitive-behavioral therapies for chronic pain.

\section{References}

1. Ackermann R, DeRubeis RJ: Is depressive realism real? Clin Psychol Rev 11:565-584, 1991

2. Block AR, Kremer EF, Gaylor M: Behavioral treatment of chronic pain: the spouse as a discriminative cue for pain behavior. Pain 9:243-252, 1980

3. Dura JR, Beck SJ: A comparison of family functioning when mothers have chronic pain. Pain 35:79-89, 1988

4. Flor H, Kerns RD, Turk DC: The role of spouse reinforcement, perceived pain, and activity levels of chronic pain patients. J Psychosom Res 31:251-259, 1987 
5. Gil KM, Keefe FJ, Crisson JE, Van Dalfsen PJ: Social support and pain behavior. Pain 29:209-217, 1987

6. Grushka M, Sessle BJ: Applicability of the McGill Pain Questionnaire to the differentiation of "toothache" pain. Pain 19:49-57, 1984

7. Hanson RW, Gerber KE: Coping with chronic pain, a guide to patient self-management. p. 232. Guilford Press, New York, 1990

8. Janovic J, Glass JP: Metoclopramine-induced phantom dyskinesia. Neurology 35:432-435, 1985

9. Jerome A, Holroyd KA, Theofanous AG et al: Cluster headache pain vs. other vascular headache pain: differences revealed with two approaches to the McGill Pain Questionnaire. Pain 34:35-42, 1988

10. Katz J: The reality of phantom limbs. Mot Emot $17: 147-179,1993$

11. Kerns RD, Haythornthwaite J, Southwick S, Giller EL Jr: The role of marital interaction in chronic pain and depressive symptom severity. J Psychosom Res 34:401-408, 1990

12. Lousberg R, Schmidt AJM, Groenman NH: The relationship between spouse solicitousness and pain behavior: searching for more experimental evidence. Pain 51:75-79, 1992

13. Masson EA, Hunt L, Gem JM, Boulton AJM: A novel approach to the diagnosis and assessment of symptomatic diabetic neuropathy. Pain 38:25-28, 1989
14. Melzack R, Katz J: Pain measurement in persons in pain. pp. 337-351. In Wall PD, Melzack R (eds): Textbook of pain. 3rd ed. Churchill Livingstone, Edinburgh, 1994

15. Melzack R, Terrence C, Fromm G, Amsel R: Trigeminal neuralgia and atypical facial pain: use of the McGill Pain Questionnaire for discrimination and diagnosis. Pain 27:297-302, 1986

16. Muse M: Stress-related posttraumatic chronic pain syndrome: behavioral treatment approach. Pain 25:389-394, 1986

17. Raphael KG, Dohrenwend BP, Marbach JJ: Illness and injury among children of temporomandibular pain and dysfunction syndrome (TMPDS) patients. Pain 40:61-64, 1990

18. Rickard K: The occurrence of maladaptive health-related behaviors and teacher-rated conduct problems in children of chronic low back pain patients. J Behav Med 11:107-116, 1988

19. Romano JM, Turner JA, Friedman LS et al: Sequential analysis of chronic pain behaviors and spouses responses. J Consult Clin Psychol 60:777-782, 1992

20. Shedler J, Mayman M, Manis M: The illusion of mental health. Am Psychol 48:1117-1131, 1993

21. Turk DC, Meichenbaum D: A cognitive-behavioural approach to pain management. p. 1337-1348. In Wall PD, Melzack R (eds): Textbook of pain. 3rd ed. Churchill Livingstone, Edinburgh, 1994

22. Watzlawick P, Helmick Beaven J, Jackson DD: Pragmatics of human communication. W.W. Norton, New York, 1967 